\title{
Research Article \\ Fracture Property of Y-Shaped Cracks of Brittle Materials under Compression
}

\author{
Xiaoyan Zhang, Zheming Zhu, and Hongjie Liu \\ Department of Engineering Mechanics, Sichuan University, Chengdu 610065, China \\ Correspondence should be addressed to Zheming Zhu; zhuzm1965@163.com
}

Received 11 March 2014; Accepted 23 May 2014; Published 9 June 2014

Academic Editor: Xiao-wei Gao

Copyright (c) 2014 Xiaoyan Zhang et al. This is an open access article distributed under the Creative Commons Attribution License, which permits unrestricted use, distribution, and reproduction in any medium, provided the original work is properly cited.

\begin{abstract}
In order to investigate the properties of Y-shaped cracks of brittle materials under compression, compression tests by using square cement mortar specimens with Y-shaped crack were conducted. A true triaxial loading device was applied in the tests, and the major principle stresses or the critical stresses were measured. The results show that as the branch angle $\theta$ between the branch crack and the stem crack is $75^{\circ}$, the cracked specimen has the lowest strength. In order to explain the test results, numerical models of Y-shaped cracks by using ABAQUS code were established, and the J-integral method was applied in calculating crack tip stress intensity factor (SIF). The results show that when the branch angle $\theta$ increases, the SIF $K_{\mathrm{I}}$ of the branch crack increases from negative to positive and the absolute value $K_{\mathrm{II}}$ of the branch crack first increases, and as $\theta$ is $50^{\circ}$, it is the maximum, and then it decreases. Finally, in order to further investigate the stress distribution around Y-shaped cracks, photoelastic tests were conducted, and the test results generally agree with the compressive test results.
\end{abstract}

\section{Introduction}

Cracks are frequently encountered in many engineering structures, such as rock and concrete, and such cracks usually play a dominative role in structure stability. In order to predict and prevent engineering disasters induced by such cracks, it is necessary to investigate the properties of crack propagation so as to obtain a better understanding of the dominant parameters that control material fracturing. Therefore, a great deal of efforts from theoretical and experimental points of view has been devoted to the study of the physics of crack fracture, and accordingly many significant results have been presented in the literatures [1-5].

Cracks are not always straight, and they may have many different shapes, such as curved cracks, intersected cracks, and branched cracks. Y-shaped crack is one kind of branched cracks and exists widely in structures because they are easily developed as two cracks intersect or coalesce. For the problem of multiple interacting cracks in an infinite plate, Yavuz et al. [6] formulated the stress intensity factor (SIF) by using integral equations expressed in terms of unknown edge dislocation along crack lines, and finally some new and challenging crack interaction problems including branched Y-cracks, two-kinked V-cracks were analyzed. For symmetry Y-shaped cracks under compression, Li and Zhu [7] reported that there is a particular relation between the crack angle and the SIF, and the results showed that the SIF at crack tips is strongly dependent both on crack angle and crack length. By using finite element method, Isida and Noguchi [8] solved the basic problems of branched cracks in an infinite body through diverse numerical methods. Moreover, also by using finite element method, several researchers [9-15] calculated the growing path and the SIF values of branched cracks. For nonstraight cracks, Tilbrook and Hoffman [16] employed a simple analytical model to predict mechanical energy release rate and deflection angle for a range of crack shapes under mixed-mode loading. It was found that the crack length and orientation of the crack tip with respect to loading direction are the key influences on fracture parameters. The experimental study of the coalescence property of two cracks under compression conducted by Bobet and Einstein [17] showed that as the vertical load increases, new cracks emanate from the flaws and eventually coalesce; flaw slippage, wing-crack initiation, secondary crack initiation, crack coalescence, and 


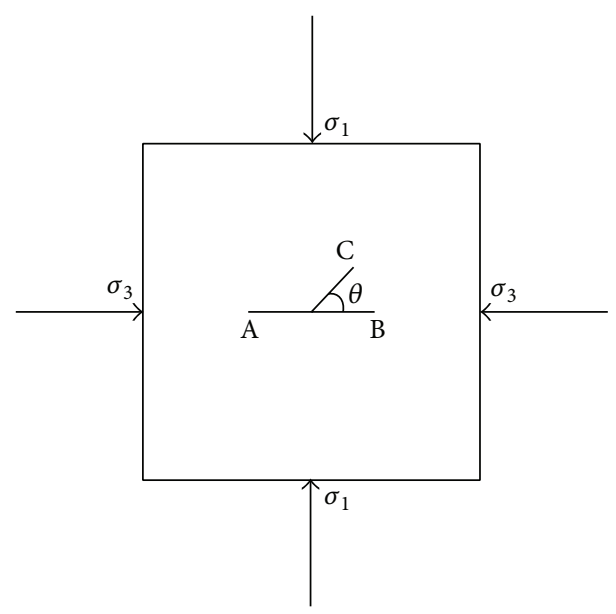

FIGURE 1: Y-shaped crack under compression.

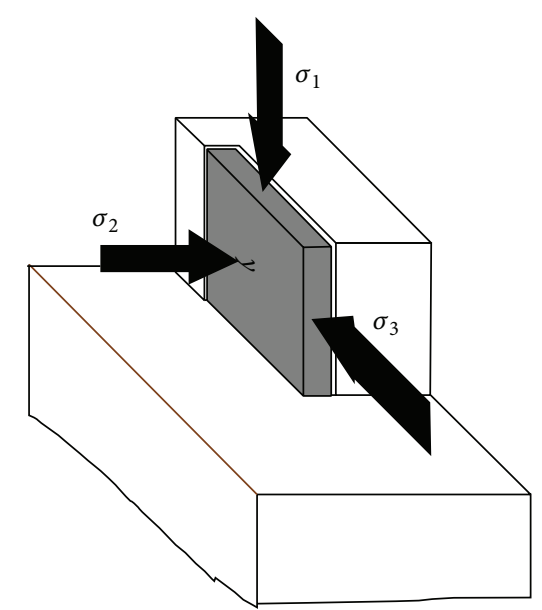

FIgURE 2: Sketch of a true triaxial loading device.

failure were observed. Two types of cracks arised: wingcracks, which are tensile cracks, and secondary cracks which initiate as shear cracks in a plane roughly coplanar with the flaw.

In order to investigate the fracture behavior of Y-shaped cracks, experimental and numerical studies are implemented in this paper. The experimental studies include true triaxial compression test and photoelastic test. A true triaxial loading device is applied in the measurement of the compressive critical stress of the cement mortar specimens with Y-shaped cracks, and meanwhile in order to qualitatively investigate the crack tip SIFs for the specimens with various branch angles, photoelastic tests are conducted. In the numerical simulation, the finite element code ABAQUS is applied in the calculation of SIF values of Y-shaped crack tips.

\section{Compression Tests}

The specimens were square plates, $150 \mathrm{~mm} * 150 \mathrm{~mm} *$ $50 \mathrm{~mm}$, with a Y-shaped artificial and penetrated crack, as shown in Figure 1. The main crack $A B$ measures $40 \mathrm{~mm}$ in length, while the branch crack measures $20 \mathrm{~mm}$, and the branch angle $\theta$ varies from $15^{\circ}$ to $90^{\circ}$. The material is cement mortar, and the ratio of cement: water : sand is $1: 0.5: 3$ by weight. The cracks were made by using a very thin, $0.1 \mathrm{~mm}$, film. The films were placed inside the samples during the process of casting in a mold until they were loaded. The curing period of the samples is 28 days. It is found that after the specimens have been stored in a heating apparatus with a controlled temperature for more than 2 hrs, the films can be easily pulled out from the specimens.

The specimens were loaded by a true triaxial loading device, as shown in Figure 2. The vertical loading is the major principal stress $\sigma_{1}$, and the two horizontal confining stresses are kept as constants during the process of vertical loading. One of the horizontal stress is $\sigma_{3}$, and the other one is $\sigma_{2}$, In order to avoid the specimen damage before testing, the specimens, at beginning, are loaded simultaneously along three directions, and after $\sigma_{2}$ and $\sigma_{3}$ are fixed to the values predesigned, we continue to increase $\sigma_{1}$ gradually until 


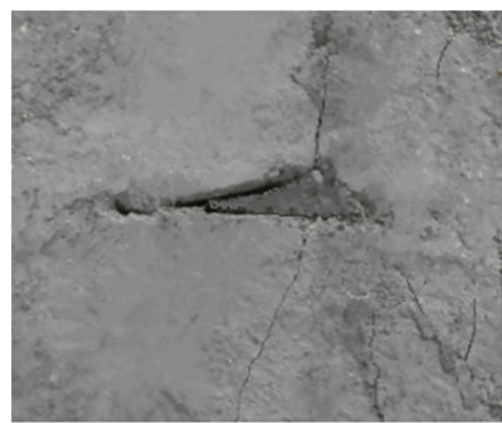

(a) $\theta=15^{\circ}$

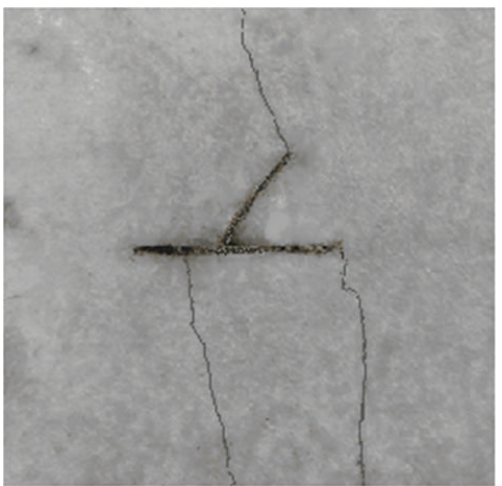

(d) $\theta=60^{\circ}$

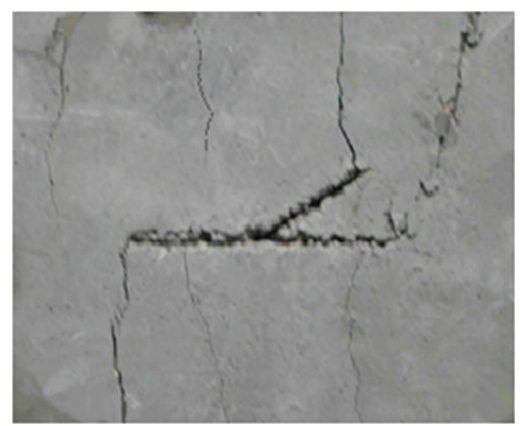

(b) $\theta=30^{\circ}$

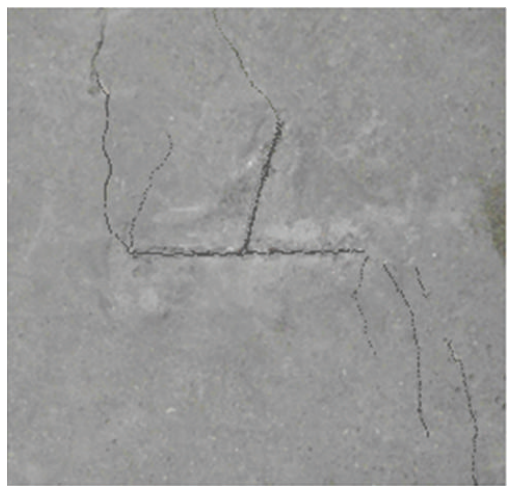

(e) $\theta=75^{\circ}$

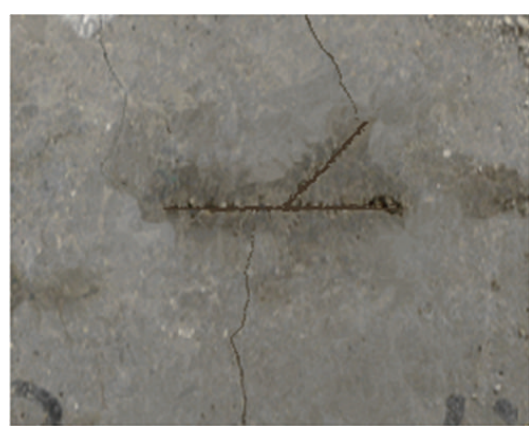

(c) $\theta=45^{\circ}$

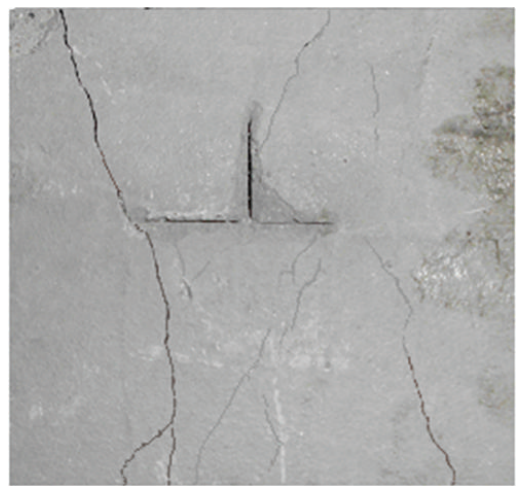

(f) $\theta=90^{\circ}$

FIGURE 3: Test result of the fracture patterns for the specimens with different branch angles.

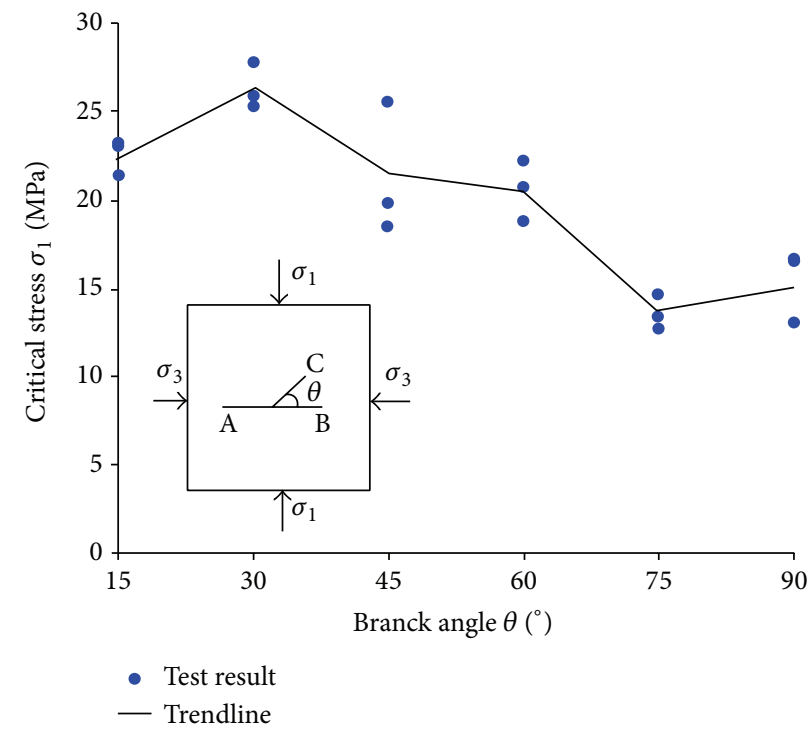

FIgURE 4: Test result for the relation between the critical stress and branch crack angles $\theta$.

the specimen fails. The maximum vertical stress $\sigma_{1}$ is selected as the critical stress of the specimens. In order to avoid the effect of the friction between the specimen and the loading device, the specimen surfaces were smeared with oil before testing.

Figure 3 shows the fracture patterns for the specimens with branch angles $15^{\circ}, 30^{\circ}, 45^{\circ}, 60^{\circ}, 75^{\circ}$, and $90^{\circ}$. It can be seen that wing-cracks often initiate at branch crack tip C and then they grow and curve to the uploading boundary of $\sigma_{1}$.

Figure 4 shows the test result of the critical stress $\sigma_{1}$ versus branch angle $\theta$. As the branch angle is $30^{\circ}$, the average test result of the critical stress is the largest, and as it increases from $30^{\circ}$ to $90^{\circ}$, the critical stress generally decreases, and as the branch angle is $75^{\circ}$, the average test result is the lowest. 


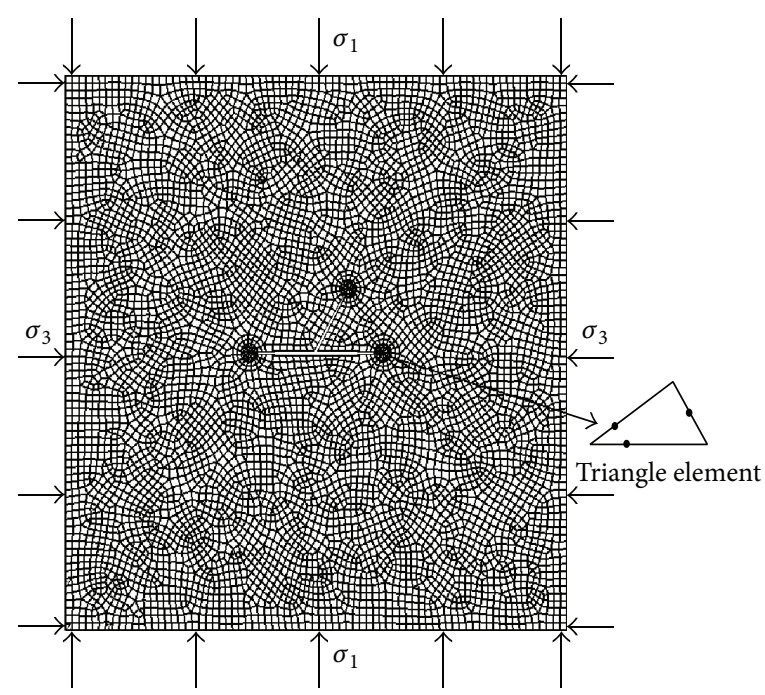

FIGURE 5: Elements applied in dividing the domain containing Y-shaped cracks.

\section{Numerical Study}

In order to obtain the stress intensity factors of asymmetric Y-shaped cracks, the corresponding numerical study by using ABAQUS code was implemented. In this simulation, except for the zone near crack tips where triangular elements CPS6 were applied, quadrilateral elements CPS8 were employed, as shown in Figure 5. The J-integral or contour integral method was applied in calculating crack tip stress intensity factor (SIF), and the material parameters applied in this numerical study are as follows. Young's modulus is $29.5 \mathrm{GPa}$; Poisson's ratio is 0.2 ; the major principal stress $\sigma_{1}$ is $1.0 \mathrm{MPa}$; and $\sigma_{3}$ is $0.05 \mathrm{MPa}$. In Total 20 models with different branch angles were established, and the corresponding calculation results are plotted in Figures 6 and 7. For the branch angle $\theta$ is $15^{\circ}, 30^{\circ}, 45^{\circ}, 60^{\circ}, 75^{\circ}$, and $90^{\circ}$; the corresponding calculation results of SIF values at crack tips $\mathrm{A}, \mathrm{B}$, and $\mathrm{C}$ are presented in Table 1.

It can be seen that the values of $K_{\mathrm{I}}$ at crack tips A and B are always negative. This is because under compression, there is no stress concentration at crack tips, and accordingly the mode I SIF is negative which cannot cause crack propagation. The values of $K_{\mathrm{I}}$ at crack tip $\mathrm{C}$ increase as the branch angles $\theta$ increase, and as $\theta$ is larger than $65^{\circ}$, the $K_{\mathrm{I}}$ changes from negative to positive which could cause crack propagation.

The mode II SIFs $K_{\mathrm{II}}$ changes with the branch angle $\theta$, and the absolute value of $K_{\mathrm{II}}$ at crack tip A increases slightly with the branch angle $\theta$. This is due to the effect from tip $\mathrm{C}$ which increases as $\theta$ increases. As $\theta=90^{\circ}$, the absolute values of $K_{\text {II }}$ at crack tips $\mathrm{A}$ and $\mathrm{B}$ are roughly equal, but their signs are inverse. The absolute value of $K_{\mathrm{II}}$ at crack tip C increases as $\theta$ increases from $0^{\circ}$ to $50^{\circ}$, and as $\theta=50^{\circ}$, the $K_{\mathrm{I}}$ absolute value is the maximum and then it starts to decrease as $\theta$ increases from $50^{\circ}$ to $90^{\circ}$.

From Figures 5 and 6, one can find that for the branch $\operatorname{crack} \mathrm{C}$, as $\theta$ is larger than $65^{\circ}$, the values of $K_{\mathrm{I}}$ is positive, and meanwhile the absolute values of $K_{\mathrm{II}}$ is large. Combing the values of $K_{\mathrm{I}}$ and $K_{\mathrm{II}}$, one can find that as the branch angle $\theta$ is
TABLE 1: Calculation results of SIF $\left(\mathrm{MPa} * \mathrm{~m}^{1 / 2}\right)$ from ABAQUS code.

\begin{tabular}{lcccccc}
\hline \multirow{2}{*}{ Angle } & \multicolumn{2}{c}{ Crack A } & \multicolumn{2}{c}{ Crack B } & \multicolumn{2}{c}{ Crack C } \\
& $K_{\mathrm{I}}$ & $K_{\mathrm{II}}$ & $K_{\mathrm{I}}$ & $K_{\mathrm{II}}$ & $K_{\mathrm{I}}$ & $K_{\mathrm{II}}$ \\
\hline $15^{\circ}$ & -0.270 & -0.002 & -0.22 & -0.018 & -0.168 & -0.010 \\
$30^{\circ}$ & -0.271 & -0.008 & -0.247 & 0.001 & -0.124 & -0.051 \\
$45^{\circ}$ & -0.272 & -0.017 & -0.265 & 0.017 & -0.067 & -0.068 \\
$60^{\circ}$ & -0.273 & -0.026 & -0.275 & 0.029 & -0.013 & -0.067 \\
$75^{\circ}$ & -0.276 & -0.034 & -0.279 & 0.036 & 0.026 & -0.039 \\
$90^{\circ}$ & -0.279 & -0.038 & -0.279 & 0.038 & 0.041 & 0 \\
\hline
\end{tabular}

in the range between $70^{\circ}$ and $75^{\circ}$, the compressive strength of the cracked sample should be low, which agrees with the test results shown in Figure 4.

\section{Photoelastic Tests}

Photoelasticity is an experimental technique for stress and strain analysis that is particularly useful for the samples with a complex geometry and loading conditions. It is a nondestructive, whole-field, graphic stress-analysis technique based on an optical mechanical property called birefringence $[18,19]$.

According to the standard of marking photoelastic specimen method, a group of specimens as shown in Figure 1 with the inclined angles $0^{\circ}, 15^{\circ}, 30^{\circ}, 45^{\circ}, 60^{\circ}, 75^{\circ}$, and $90^{\circ}$ are conducted, respectively. The material was polycarbonate (PC) which possesses high transparency. The size of the specimen was $100 \mathrm{~mm} * 100 \mathrm{~mm} * 8 \mathrm{~mm}$, and the width of cracks in the specimens was $1 \mathrm{~mm}$.

According to stress-optical law of plane photoelastic experiment, the maximum shear stress $\tau_{m}$ can be calculated based on the following equation:

$$
\tau_{m}=\frac{1}{2}\left(\sigma_{1}-\sigma_{3}\right)=\frac{N f_{\sigma}}{2 h},
$$




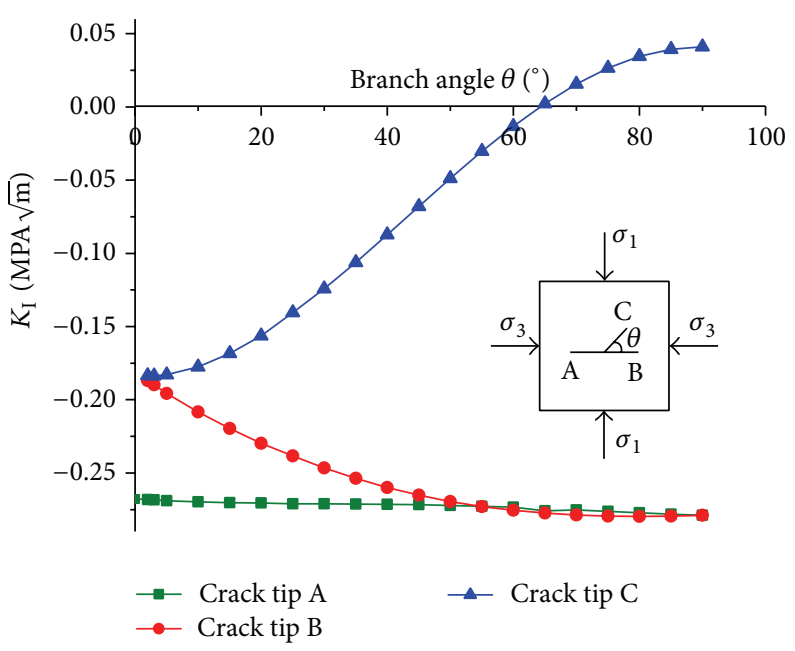

FIgURE 6: Curves of SIF $K_{\mathrm{I}}$ versus the branch angle $\theta$.

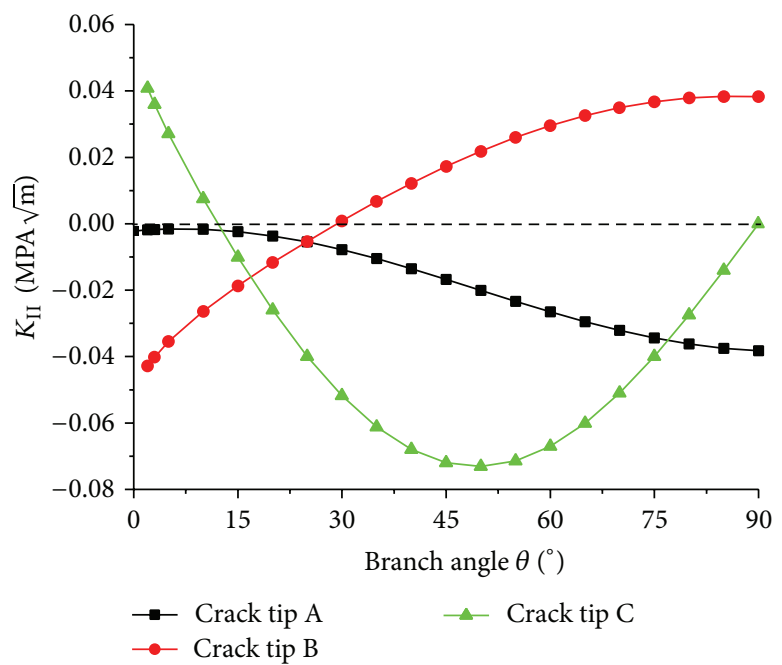

FIGURE 7: Curves of SIF $K_{\text {II }}$ versus the branch angle $\theta$.

where $N$ is the number of isochromatic fringes, $f_{\sigma}$ is fringe value, and $h$ is the thickness of specimen.

Figure 8 shows the test results of isochromatic fringes for the specimens with different branch angles $\theta$. It can be seen that as $\theta$ increases, the fringes number near crack tips increases gradually, which means that crack SIF values increase, and as the branch angle is in the range between $60^{\circ}$ and $75^{\circ}$, the fringes number is more. This means that the compressive strength is low, which can be proved from the test results of the compressive strength shown in Figure 4.

\section{Conclusion}

In order to study the fracture property of Y-shaped cracks under compression, compression tests by using a true triaxial loading device and the corresponding photoelastic experiments have been conducted. The stress intensity factors of
Y-shaped cracks have been calculated by using ABAQUS code. In the numerical study, J-integration method has been applied in calculating stress intensity factors. Through the experimental and numerical studies, the following conclusions can be obtained.

(1) For a Y-shaped crack under compression, at tips A and $\mathrm{B}$, the mode I SIFs are always negative which will not induce fracturing, and their maximum mode II SIFs are much less than those at tip C.

(2) As the branch angle is larger than $65^{\circ}$, the mode I SIF at tip $\mathrm{C}$ is positive, and as the branch angle is $50^{\circ}$, tip C has the largest $K_{\text {II }}$ value.

(3) The critical stress changes with the branch angles, and as the branch angle increases from $15^{\circ}$ to $75^{\circ}$, the critical stress decreases, and as the branch angle is $30^{\circ}$, the principle stress is the largest, and as it is $75^{\circ}$, the principle stress is the lowest. 


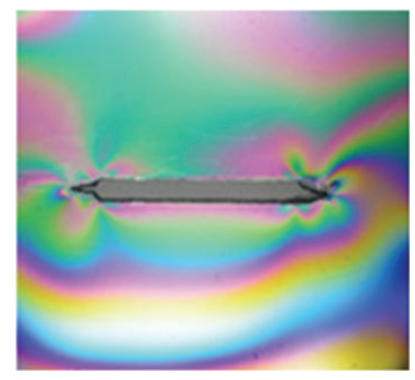

(a) $\theta=0^{\circ}$

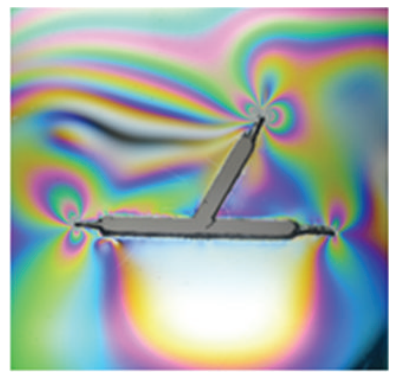

(e) $\theta=60^{\circ}$

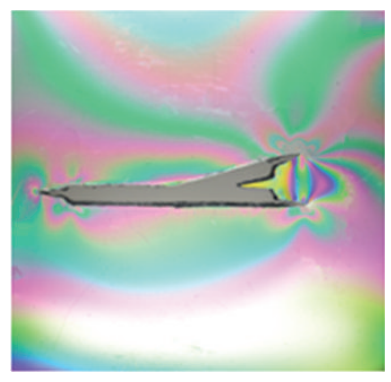

(b) $\theta=15^{\circ}$

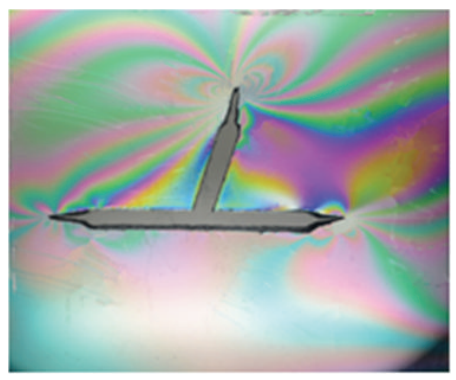

(f) $\theta=75^{\circ}$

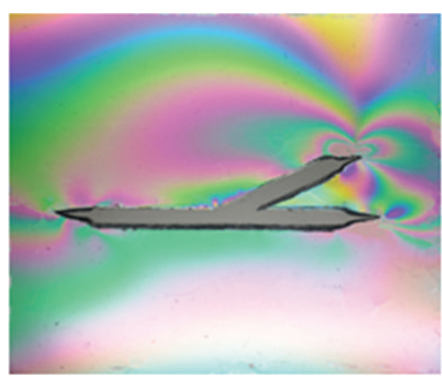

(c) $\theta=30^{\circ}$

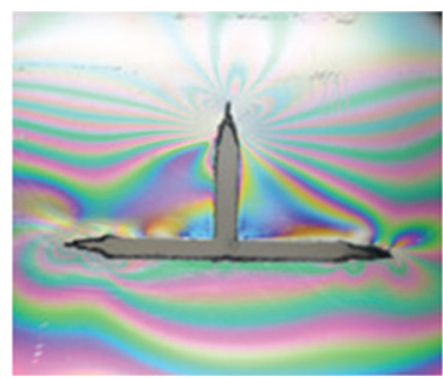

(g) $\theta=90^{\circ}$

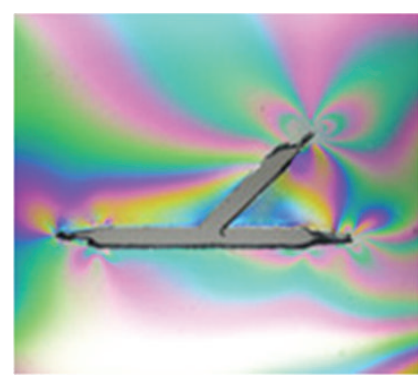

(d) $\theta=45^{\circ}$

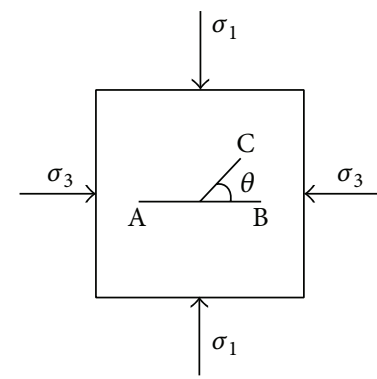

(h)

FIGURE 8: Isochromatic fringes of Y-shaped cracks under biaxial compression.

\section{Conflict of Interests}

The authors declare that there is no conflict of interests regarding the publication of this paper.

\section{Acknowledgments}

This work was financially supported by the Open Fund of State Key Laboratory of Oil and Gas Reservoir Geology and Exploitation (PLN1202), by the project of Science and Technology of Sichuan province (2014JY0002), and by the Major State Basic Research Project (2010CB732005).

\section{References}

[1] S. Nemat-Nasser and H. Horii, "Compression-induced nonplanar crack extension with application to splitting, exfoliation, and rockburst," Journal of Geophysical Research, vol. 87, no. 8, pp. 6805-6821, 1982.

[2] Z. M. Zhu, L. Wang, B. Mohanty, and C. Huang, "Stress intensity factor for a cracked specimen under compression," Engineering Fracture Mechanics, vol. 73, no. 4, pp. 482-489, 2006.

[3] Z. M. Zhu, "An alternative form of propagation criterion for two collinear cracks under compression," Mathematics and Mechanics of Solids, vol. 14, no. 8, pp. 727-746, 2009.

[4] Z. M. Zhu, "New biaxial failure criterion for brittle materials in compression," Journal of Engineering Mechanics, ASCE, vol. 125, no. 11, pp. 1251-1258, 1999.

[5] P. Baud, T. Reuschlé, and P. Charlez, "An improved wing crack model for the deformation and failure of rock in compression," International Journal of Rock Mechanics and Mining Sciences and Geomechanics, vol. 33, no. 5, pp. 539-542, 1996.

[6] A. K. Yavuz, S. L. Phoenix, and S. C. Termaath, "An accurate and fast analysis for strongly interacting multiple crack configurations including kinked (V) and branched (Y) cracks," International Journal of Solids and Structures, vol. 43, no. 22-23, pp. 6727-6750, 2006.

[7] B.-Y. Li and Z.-M. Zhu, "Numerical and experimental research on the fracture and propagation of the branch crack under compression," Journal of China Coal Society, vol. 38, no. 7, pp. 1207-1214, 2013.

[8] M. Isida and H. Noguchi, "Stress intensity factors at tips of branched cracks under various loadings," International Journal of Fracture, vol. 54, no. 4, pp. 293-316, 1992.

[9] Y. K. Cheung, C. W. Woo, and Y. H. Wang, "A general method for multiple crack problems in a finite plate," Computational Mechanics, vol. 10, no. 5, pp. 335-343, 1992.

[10] C. Colombo and L. Vergani, "A numerical and experimental study of crack tip shielding in presence of overloads," Engineering Fracture Mechanics, vol. 77, no. 11, pp. 1644-1655, 2010.

[11] C. W. Smith and O. Olaosebikan, "Use of mixed-mode stress-intensity algorithms for photoelastic data," Experimental Mechanics, vol. 24, no. 4, pp. 300-307, 1984.

[12] C. W. Smith, J. J. McGowan, and M. Jolles, "Effects of artificial cracks and poisson's ratio upon photoelastic stress-intensity determination," Experimental Mechanics, vol. 16, no. 5, pp. 188193, 1976.

[13] D.-C. Shin, J.-H. Nam, J.-S. Hawong, and J.-H. Lee, "Influences of equal biaxial tensile loads on the stress fields near the mixed mode crack," Journal of Mechanical Science and Technology, vol. 23, no. 8, pp. 2320-2329, 2009.

[14] I. Katsuhiko, "New model materials for photo," Experimental Mechanics, vol. 2, pp. 373-376, 1962.

[15] G. R. Irwin, "Analysis of stresses and strains near the end of a crack traversing a plate," Journal of Applied Mechanics, vol. 24, pp. 361-364, 1957.

[16] M. Tilbrook and M. Hoffman, "Approximation of curved cracks under mixed-mode loading," Engineering Fracture Mechanics, vol. 74, no. 7, pp. 1026-1040, 2007. 
[17] A. Bobet and H. H. Einstein, "Fracture coalescence in rocktype materials under uniaxial and biaxial compression," International Journal of Rock Mechanics and Mining Sciences, vol. 35, no. 7, pp. 863-888, 1998.

[18] R. Patyñska and J. Kabiesz, "Scale of seismic and rock burst hazard in the Silesian companies in Poland," Mining Science and Technology, vol. 19, no. 5, pp. 604-608, 2009.

[19] Z. P. Zhang, "Mixed mode stress intensity factors from photoelastic five-parameter method," Chinese Journal of Applied Mechanics, vol. 17, pp. 80-86, 2000. 

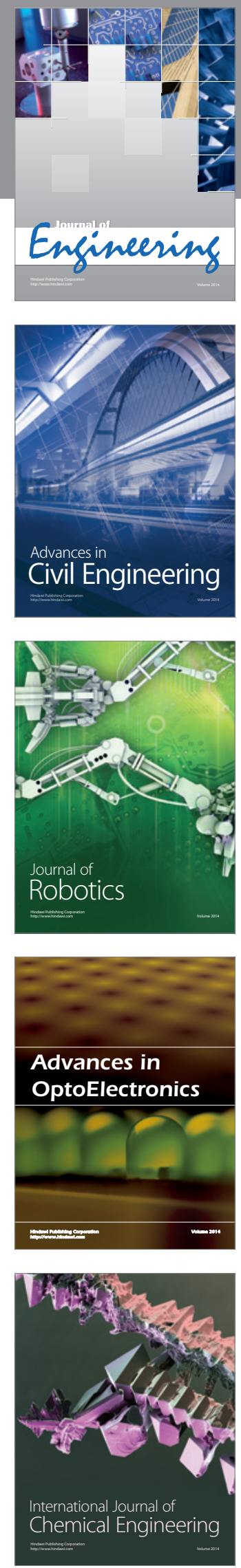

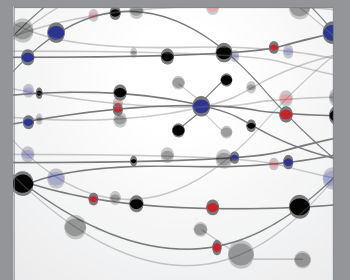

The Scientific World Journal
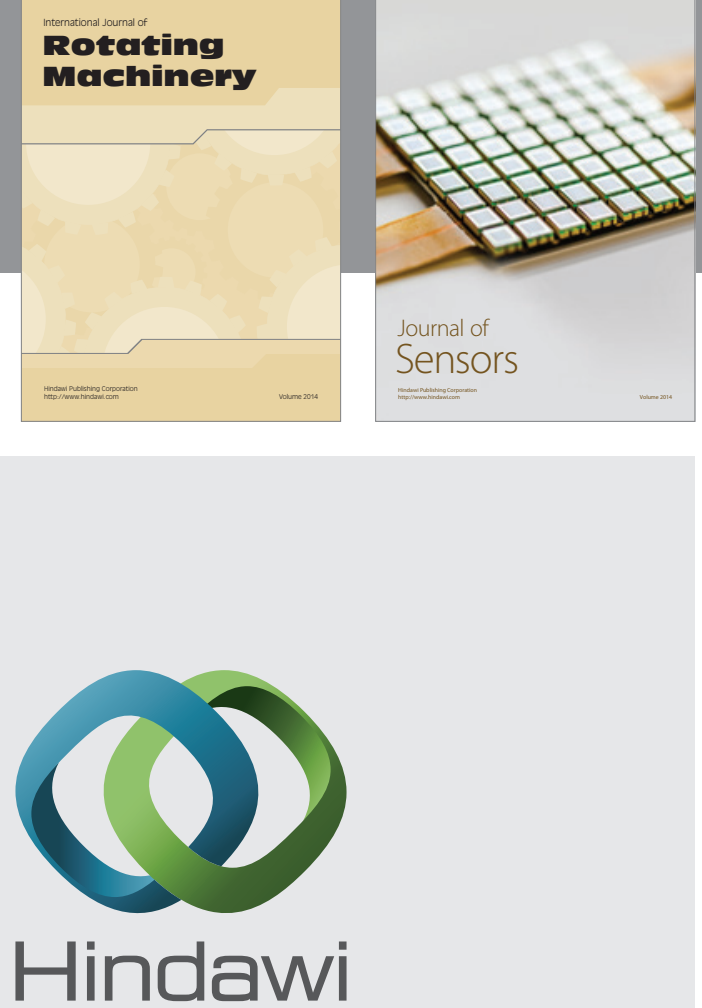

Submit your manuscripts at http://www.hindawi.com
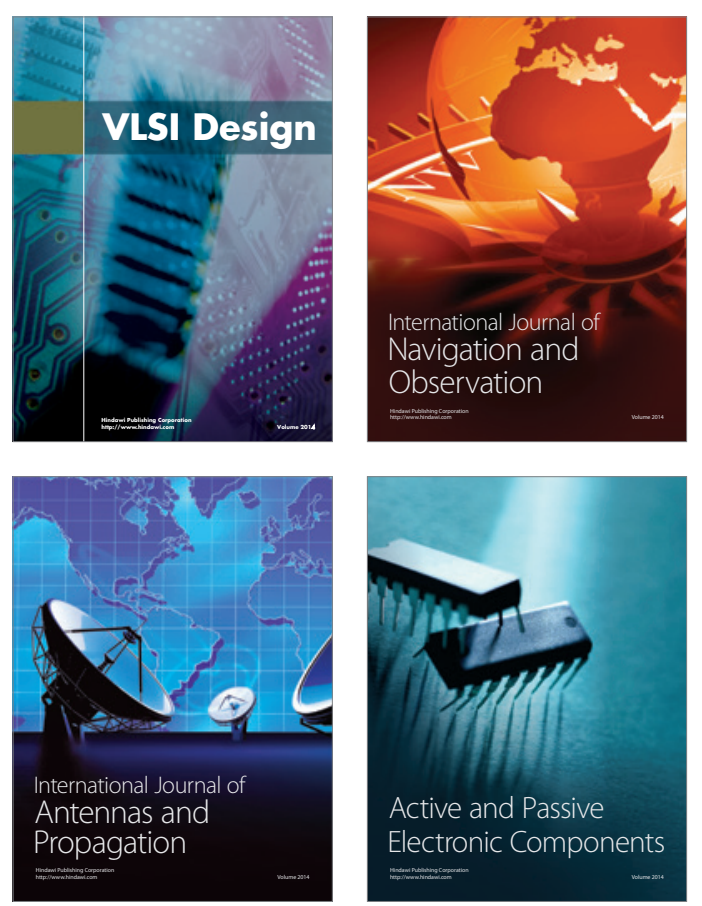
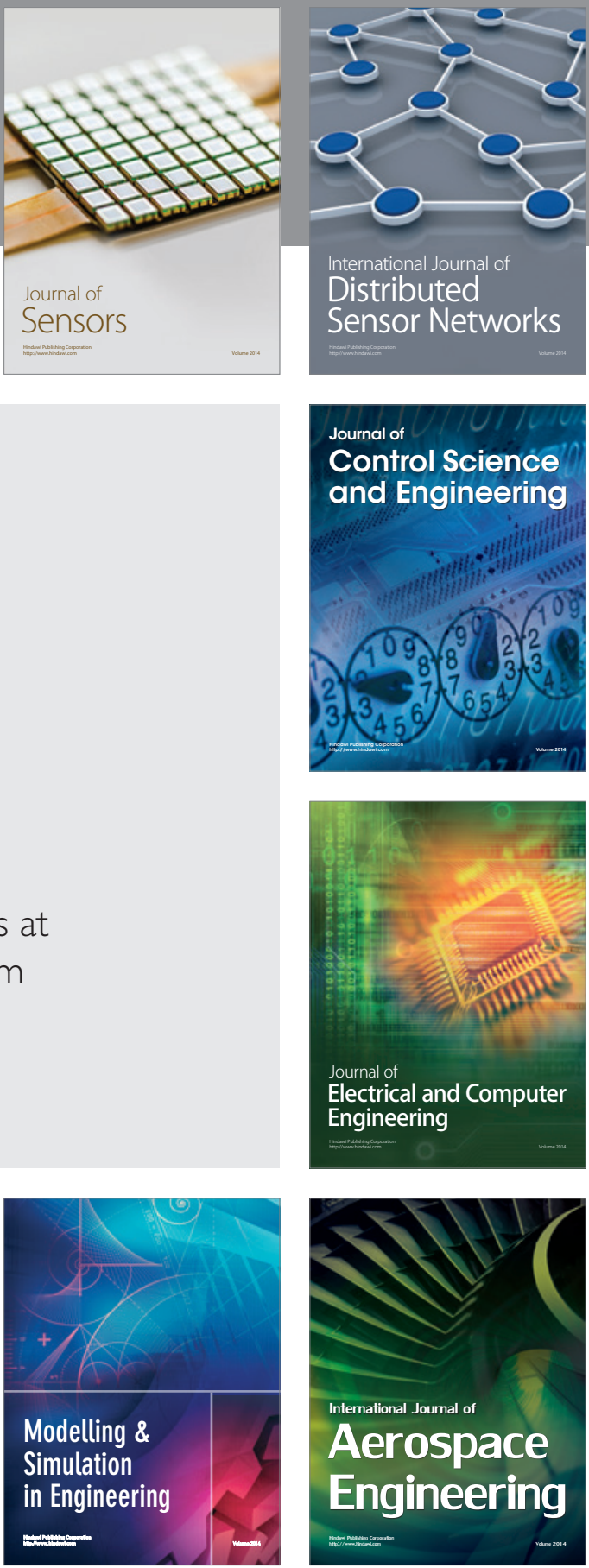

Journal of

Control Science

and Engineering
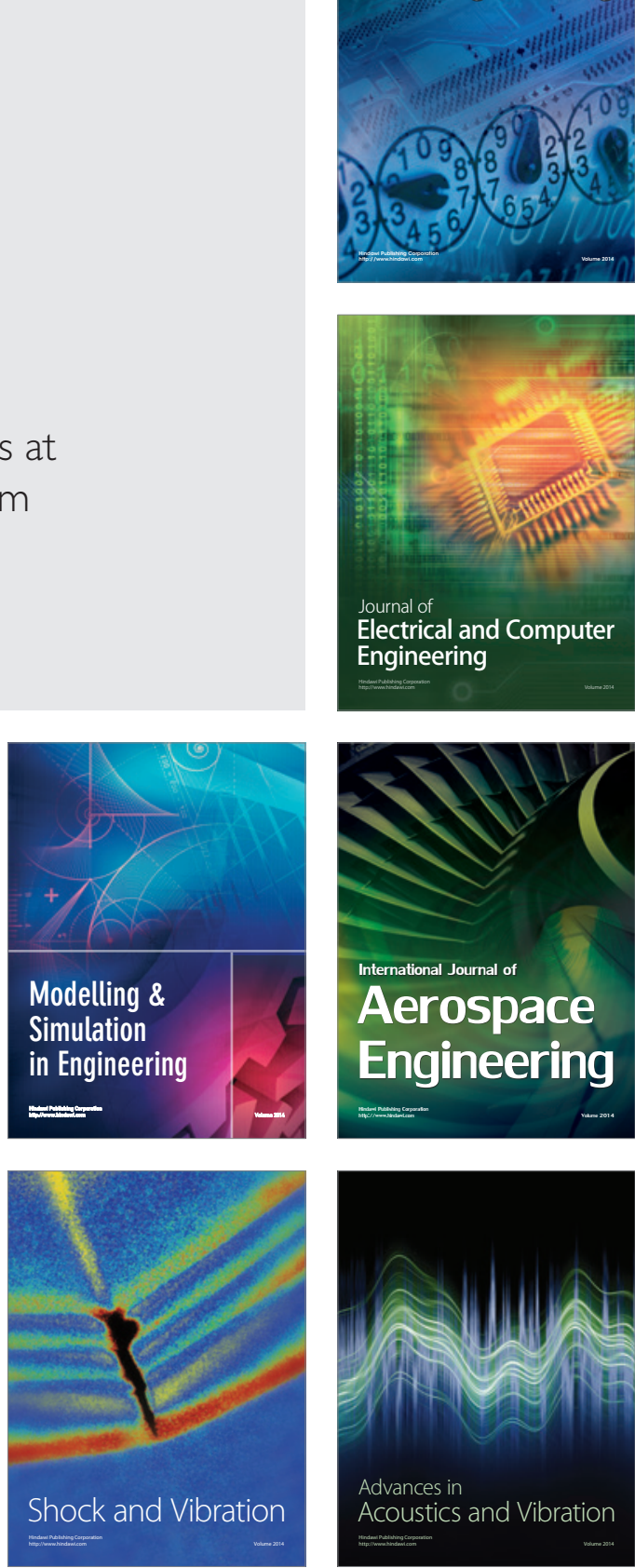